\title{
DEVELOPMENT OF THE INTEGRATED APPROACH TO THE LOCATION OF CHARGING INFRASTRUCTURE IN TYUMEN CITY, RUSSIAN FEDERATION
}

\author{
ANASTASIYA GORBUNOVA \& ILYA ANISIMOV \\ Industrial University of Tyumen, Russian Federation
}

\begin{abstract}
Over the past 10 years, the fleet of electric vehicles has grown dramatically, due to the introduction of incentive programs for their operation, as well as the development of accessible charging infrastructure. However, the design and organization of this network come with a number of obstacles in countries where the number of electric vehicles is limited. A small number of operated electric vehicles leads to a decrease in the utilization rate of the charging infrastructure. A main obstacle to increasing the fleet of electric vehicles is an insufficiently developed charging network. In this instance, such a location of charging stations in the city that will help to reduce idle runs of electric vehicles and increase the utilization rates of charging stations is one of the priority practical tasks in the field of infrastructure organization. In the world, there are approaches to the location of charging stations in cities. They are based on the methods proposed for choosing the location of socially significant objects in the city, and therefore take into account the centres of attraction of the population, the features of the organization of parking space and car services. However, until now, no methodology has been developed aimed at calculating the number of charging stations in the city, taking into account the characteristics of the functioning of the existing infrastructure and their location. The developed approach to the location of charging stations will take into account the peculiarities of the city's power distribution network, the complexity of the access roads to the charging station and the likelihood of a free parking space. This paper partially describes the results of a larger study and aims at developing an approach to the location of charging stations in the city and optimizing the existing network. The approach was developed in two stages. Initially, the authors identified the applicability of an existing model, and then at the second stage, they adapted it taking into account the proposed indicators for assessing the location of the charging station in the city of Tyumen. In the future, the developed approach will be applied in several cities of the Russian Federation.

Keywords: capital costs, charging infrastructure, charging station, electric vehicle, model of the optimal location, operating costs.
\end{abstract}

\section{INTRODUCTION}

A growing fleet of electric vehicles is an integral part of the development of the automotive industry. As of 1 January 2020, this value exceeded 7 million units. In the future, it may reach 160 million electric vehicles globally [1-2]. The reasons for this lie in the active implementation of programs to improve the environmental compatibility of vehicles, as well as to stimulate the acquisition and operation of electric vehicles, which may include programs for the development of the charging infrastructure. At the end of 2018, the number of charging stations in the world exceeded 5 million [3-5]. Most of them are concentrated in several leading countries [6-9]. In most countries, charging infrastructure is developed unevenly. So, in the Russian Federation, the most developed infrastructure is located in the largest cities, and in more remote ones it may be non-existent. Here, the following contradiction is observed: with a small number of operated electric vehicles, charging stations have a low utilization rate, and, therefore, have a low revenue, which slows down the development of the network. However, the lack of a developed network of charging stations is an obstacle to the increase in the number of electric vehicles. According to the opinion presented in [10], in this context, a priority task of organizing the studied infrastructure is the location of a limited number 
of charging stations in the city. This will reduce idle runs for electric vehicle owners and increase demand for charging stations.

The existing algorithms for the location of charging stations in cities are based on the application and combination of approaches proposed by Daskin M.S. to locate the socially significant objects in the city, which should contribute to the reduction of overruns in order to achieve them and have a maximum transport demand [11,12]. In this case, the maximum demand is achieved as a result of their location in the nodes of the road network that have the maximum demand, taking into account the nearby nodes (at a distance not exceeding the maximum coverage distance). However, to determine the optimal location of charging stations in cities, this approach is supplemented and adapted to the peculiarities of vehicle operation, one of which is the availability of parking space for parking during charging. This feature was taken into account in [13] when locating a model for the location of slow charging stations. The authors suggested dividing the city into several census blocks and locating charging stations in each of the allocated areas, taking into account the allocation of nodes of maximum demand. However, this approach contributes to an increase in the number of charging stations and an increase in capital costs for the creation of the infrastructure under consideration. This is due to the lack of the ability to account for work-related movements of the population during the day, which in some cases leads to duplication of charging stations in residential and business areas of the city. This feature of the developed model was taken into account in [10]. The authors created a model that was based on data on the parking of electric vehicles at night and during the day. The charging station was installed either in a business or residential area. This helped to reduce the capital costs of building the charging infrastructure. The selection of one of the proposed locations of the charging station, namely, only near office centres, was presented in [14]. At the same time, the authors proposed an additional calculation of the number of chargers based on data on the number of parking spaces and employees with electric vehicles, as well as their walking accessibility and the cost of installing the charging station and its maintenance.

The maximum satisfaction of the demand of owners of electric vehicles for battery charging can also be achieved using the p-median model. It assumes that charging stations are located based on the cost of reaching a nearby charging station (which is directly proportional to distance). This approach was originally used to locate charging stations for commercial vehicles [15]. This was due to the fact that this model allows one to reduce the cost of moving vehicles between charging stations and destinations for electric vehicles - taxis. Currently, this approach is applied in the field of public charging infrastructure [16]. It takes into account not only the nodes of maximum demand and the distance between them but also includes finding a location that will correspond to the centres of attraction of the population and the minimum cost to reach the nearest charging station. However, the application of the presented approaches (maximum coverage and $p$-median) requires a mandatory calculation of the number of charging stations that will correspond to the minimum operating and capital costs of the infrastructure under consideration [11].

Determination of the optimal location and calculation of the number of charging stations was carried out [17]. To solve the problem, the authors proposed to use agent-based modelling, which made it possible to take into account the number and location of places of concentration of electric vehicle owners based on data on the features of their movement and behaviour scenarios. However, a large amount of initial data and the complexity of predicting the behaviour of electric vehicle owners lead to difficulties in applying this approach. 
According to [18], minimization of capital and operating costs when organizing the charging network can be achieved not only by calculating the number of stations but also by determining their optimal location consistent with the features of the distribution city network [18]. As a result, the authors proposed a model in which the initial data are the features of the road network, the traffic flow in its nodes, as well as the location of transformer substations as initial data. A similar approach was presented in [19-24]. In this case, the authors suggested that installing fast-charging stations at existing gas stations could minimize the capital cost of their installation. However, the selected locations of the charging stations in this case may not always correspond to the maximum traffic flow and contribute to an increase in the utilization of the charging station.

The existing approaches to the optimal location of charging stations partially take into account the features of the location of the centres of attraction of the population in the city, the peculiarities of the road network and the electrical distribution network, and transport demand at the nodes. But they are not an integrated method that will simultaneously take into account these parameters and will help to increase the level of satisfaction of the demand of electric vehicle owners with a limited number of charging stations. The existing methods do not consider the complexity of the access road to the charging station, which can be seen in the cities of the Russian Federation. This is also one of the parameters contributing to the reduced utilization rate of the charging station, as evidenced by the results obtained during the analysis of data on the functioning of the existing charging infrastructure.

The features of the functioning of the charging infrastructure when developing a methodology for its further formation, as a rule, is studied in the field of organizing public electric transport. So, in [25], it is noted that the analysis of the existing charging network allows one to reduce operating costs and increase efficiency in the course of its planning and further development. When analysing the existing charging infrastructure, the authors determine the number and type of charging stations, as well as the specifics of their location in the existing bus network [26,27]. The initial data for the calculation are the speed and slope of the road, the length of the route, the number of passengers, the operation of auxiliary equipment, and more.

This article proposes an algorithm for optimizing the location of existing charging stations without changing their types. The influence of operating features on the parameters and the number of charging stations in the city will be considered in the following works.

The development of this algorithm is due to the lack of an integrated method that takes into account the peculiarities of the location of the centres of attraction of the population in the city, the peculiarities of the road network, the electrical distribution network and transport demand at the nodes. Additionally, it will include in the calculation data on the complexity of the access road to the charging station and help to reduce the costs of operating the network with minimal operating costs for the owners of electric vehicles.

\section{METHODOLOGY}

The algorithm to optimize the location of charging network objects in cities is being developed as one of the stages of a comprehensive methodology that provides for a preliminary calculation of the number of charging stations. This algorithm includes the model and its adaptation, which are applied to optimize the location of existing charging stations, so their type and number were predefined. 
The main provisions of the developed model were formulated in accordance with the goals set and the results of the analysis of previously performed work in the field of organizing the charging infrastructure for electric vehicles in cities. They included the following:

- minimization of capital costs for the creation of charging infrastructure;

- minimization of operating costs of a functioning charging infrastructure;

- minimization of operating costs for electric vehicle owners.

The formulated provisions were transformed in the course of the study on the basis of the results obtained in previously performed works. So, it was found that the minimum value of the installation costs of the object in question is achieved when it is located near large urban facilities with their own transformer substation. In some cases, such location corresponding to the centres of attraction of the population contributes to an increase in the utilization rate of the charging station, and, consequently, to a decrease in operating costs when operating the charging infrastructure. It also contributes to lower costs for electric vehicle owners by reducing their idle runs to charge the vehicle. However, with a limited number of these centres of attraction, it is necessary to rank them according to the level of transport demand, which necessitates the use of the maximum coverage model, or the $p$-median model.

The peculiarities of the organization of road transport infrastructure in the Russian Federation cannot ensure the maximum demand, and, consequently, the maximum utilization rate of the charging station in some cases. This is due to a complex access road or insufficient parking spaces to provide free space for unhindered charging of the electric vehicle. Therefore, these provisions were additional conditions for the development of the algorithm.

The method of its development (Fig. 1) can be presented using two main stages whose goals are the minimization of capital and operating costs for its operation and operation of electric vehicles. These stages are connected by minor intermediate stages that provide for the assessment and comparison of the results of the constructed models, as well as the analysis of the road network diagram and the assessment of the presence of complex access roads to the proposed locations of the stations.

Analysis of previous studies has shown that the maximum demand coverage model and the p-median model can be adapted to minimize operating costs for owners of charging

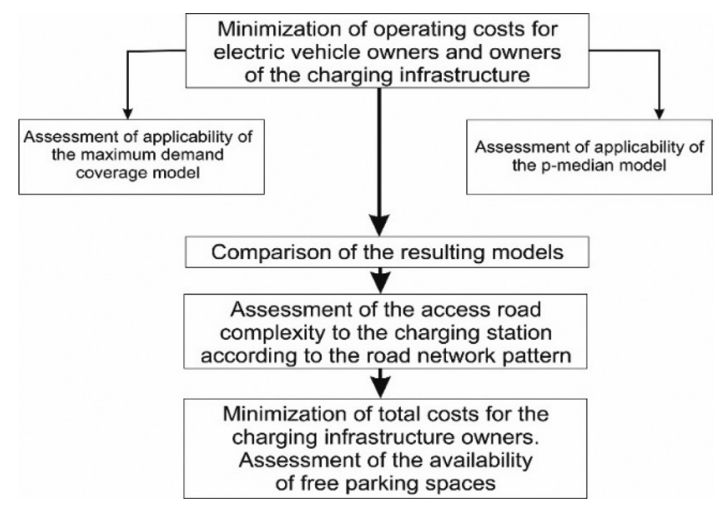

Figure 1: Diagram of model development for determining the optimal location of charging stations for electric vehicles in the city. 
infrastructure and electric vehicles. Therefore, the first stage of the study consisted in assessing the applicability of these models in the Russian Federation using the example of Tyumen and identifying the most appropriate one based on a comparison of the results obtained [28].

The maximum demand coverage model is aimed at minimizing the downtime of charging stations and increasing their utilization rate, that is, the number of vehicles served or transport demand $h_{i}$. This is reflected using objective function (1):

$$
\sum_{i \in I} h_{i} \cdot Z_{i} \rightarrow \max
$$

where $h_{i}$ - number of vehicles crossing the node $i \epsilon I, Z_{\mathrm{i}}-$ decision variable (which can be 1 or $0 ; Z_{i}=1$ when the charging station is located at a distance not exceeding the coverage distance $D_{c} ; Z_{i}=0$ when the charging station is located at distance greater than $D_{c}$ ).

This model simultaneously helps to reduce the operating costs of electric vehicle owners by limiting the distance $D_{c}$ within which the charging station can service vehicles. For this, the decision variable $Z_{i}$ is introduced into the model, which can be equal to 1 only if the distance to the nearest station does not exceed the established limit $D_{c}$. In other cases, this variable is equal to zero, which prevents the achievement of the maximum value of the covered demand.

The p-median model, in contrast to the maximum coverage model, considers the minimization of the costs for electric vehicle owners (2) and not the maximization of transport demand at the node as its objective function. This model makes it possible to simplify that the costs for electric vehicle owners are directly proportional to the distance to the nearest charging station.

$$
\sum_{i \in I} h_{i} \cdot d_{i j} \cdot Y_{i j} \rightarrow \min , \text { if } Y_{i j}=1
$$

where $d_{i j}$ - distance from the considered intersection $i \in I$ to the nearest charging station $j \in J$, $Y_{i j}$ - decision variable (which can be 1 or $0 ; Y_{i j}=1$ when the charging station $j \in J$ is used by vehicles crossing the node $i \in I ; Y_{i j}=0$ if not covered).

This model also uses a decision variable that numerically identifies the nodes of the road network for the expected location of the charging station. As a result, the p-median model is based on the statement that the maximum number of vehicles must cover the minimum distance to the charging station.

The applicability of the maximum coverage model and the p-median model is determined on the basis of a comparison of data on the total satisfied transport demand since the goal of the first stage of model development is not only to reduce the operating costs for electric vehicle owners but also to increase the utilization rate of charging stations which helps to reduce maintenance costs of the station and increase its profitability. Then, the selected model is adapted for the availability of complex access roads using the road network diagram and the features of traffic organization.

At the second stage of model development, the results obtained are used and adjusted taking into account the availability of nearby parking spaces and transformer substations. This will help to reduce the costs for the owners of the charging infrastructure for its creation and maintenance, as well as increase the attractiveness of charging stations for electric vehicle owners. At this stage, just as at the first one, the authors suggest using decision variables to assess the availability of a transformer substation and reduce the costs of creating and maintaining infrastructure $\mathrm{C}_{j}$, as well as the probability of having free parking spaces $P_{j}$. The last variable depends on the number of parking spaces, for example, $P_{j}=0$ if the number of 
parking spaces does not exceed 50, $P_{j}=1$ if the number of parking spaces is from 50 to 100 and $P_{j}=2$ if the number of parking spaces is more than 100. The availability of a transformer substation is easily assessed: $C_{j}=0$ if there is no transformer station, and $C_{j}=1$ if there is a transformer station in the parking lot.

The proposed decision variables are evaluated jointly, and their value should tend to the maximum. Mathematically, the solution to the second stage of model development is represented by formula (3):

$$
\left\{\begin{array}{c}
\left(C_{j}+P_{j}\right) \rightarrow \max \\
h_{i} \rightarrow \max
\end{array} .\right.
$$

As a result, the obtained values will make it possible to identify the expected location of the objects under consideration in the city that will correspond to the maximum transport demand, take into account the peculiarities of the traffic organization and the complexity of the access road, as well as minimize the costs of creating and maintaining stations and idle runs of electric vehicles to be charged.

The next stage of the research will consider the improvement of the presented algorithm for developing the deployment plan of charging infrastructure in Tyumen and other cities of the Russian Federation. This algorithm will take into account the climatic features of the city location, the operated fleet of electric vehicles, as well as the population' mobility and demography. As a result, it will be part of a comprehensive methodology for justifying the parameters of the charging infrastructure in the cities of the Russian Federation.

In the future, the simplicity of the further application of this technique will be provided by the software that will be developed after assessing the applicability of the model in several cities of the Russian Federation.

\section{ANALYSIS OF THE DATA}

At the first stage of the study, the existing charging infrastructure in Tyumen was studied. The authors identified its shortcomings and determined several charging stations with a low utilization rate during the day. Then, the location of charging stations in Tyumen was optimized in accordance with the above method.

\subsection{Analysis of the existing charging infrastructure in Tyumen}

In the Russian Federation, the charging infrastructure is just emerging. The most developed networks of charging stations are located in major cities, such as Moscow and St. Petersburg. Regional infrastructure lags far behind them. At the end of 2018, the city of Tyumen had one of the most developed regional charging infrastructures. The network consisted of six public charging stations. Their location is shown in Fig. 2.

The active development of the network of charging stations in the city contributed to an increase in the number of operated electric vehicles. At the same time, the difference in the shares of performed charging sessions from their total number among some charging stations increased and amounted to $17-40 \%$, which is shown in Fig. 3.

To analyse the reasons for the low utilization rate of charging stations, the features of the organization of road traffic in the area of their locations were analysed, and transport demand was calculated, which is presented in Table 1.

The results of the first stage of the study indicate that the presence of complex access roads and low transport demand reduce the utilization rate of charging stations. Therefore, it 


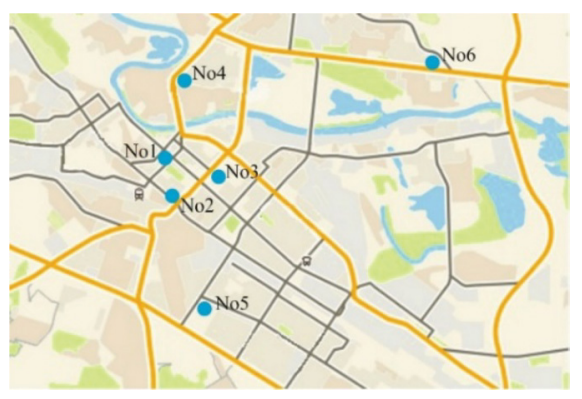

Figure 2: Layout of the charging network in Tyumen.

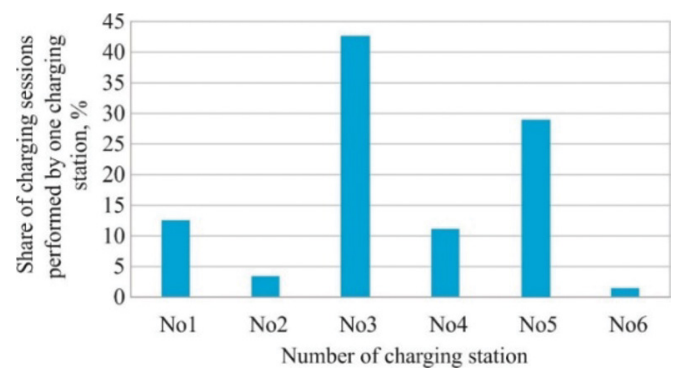

Figure 3: Distribution of charging sessions by objects of the charging network in Tyumen.

Table 1: Analysis of the covered transport demand and the complexity of the access road to the existing charging stations.

\begin{tabular}{lll}
\hline Charging station number & Transport demand, vehicles $(\mathrm{h})$ & Complex access road \\
\hline 1 & 3,108 & Yes \\
2 & 2,472 & Yes \\
3 & 5,042 & No \\
4 & 2,992 & No \\
5 & 3,693 & No \\
6 & 1,577 & No \\
\hline
\end{tabular}

was proposed to optimize the existing location of the objects under consideration using the developed method.

\subsection{Optimizing the location of charging stations in Tyumen}

One of the mandatory parameters involved in the objective functions of the maximum coverage model and the p-median model is the distance between the nodes of the road network shown in Fig. 4. Also, the initial data of the models included transport demand determined at each of the nodes indicated in Fig. 4. 


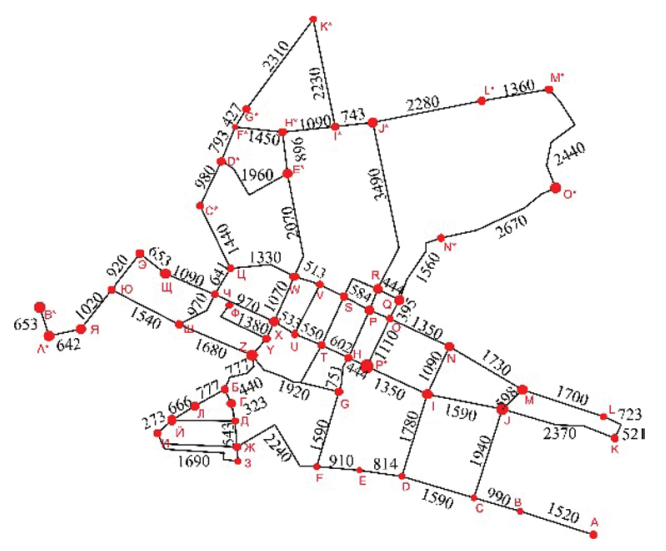

Figure 4: Layout of the road network in Tyumen.

During the construction of the maximum coverage model, the measured distances between the nodes of the road network were considered indirectly. The obtained values were compared with the maximum coverage distance, which, according to the regulatory legal acts of the Russian Federation, should not exceed $800 \mathrm{~m}$. The results of the comparison determined the value of the decision variable and, accordingly, the total transport demand in the expected charging station installation nodes (Fig. 5).

The existing charging infrastructure includes six stations. However, the number of expected stations was increased to 10, taking into account further adjustments to their location (Fig. 6). In the course of data analysis, these nodes showed a significant difference in the value of the maximum covered transport demand from other nodes.

A high proportion of population movements through the central district of Tyumen stems from the peculiarities of its road network. This leads to an increase in transport demand at its nodes and, therefore, is accompanied by a high density of charging stations. This situation will be resolved during the next stage of the model development when determining the complexity of access roads, the number of parking spaces, and the presence of transformer substations.

A high density of charging stations in the central part of the city is also observed when constructing the p-median model. However, in the example given, some objects are located in more distant areas from the city centre, which makes it possible to increase the amount of covered transport demand. In the course of building the p-median model, a matrix was created for the product of the distances between nodes and their transport demand (Fig. 7), which is due to the peculiarities of calculating the objective function.

The objective function of the p-median model should tend to a minimum. Therefore, when calculating it, the following algorithm was observed:

- search for a node with a minimum value of the sum of the products of distances and transport demand;

- zeroing all values of the calculated products in the selected node;

- repetition of the above operations.

This algorithm was repeated until 10 expected nodes (Fig. 8). 


\begin{tabular}{|c|c|c|c|c|c|c|c|c|c|c|c|c|c|c|}
\hline \multicolumn{7}{|c|}{$\begin{array}{l}\text { Distance between the node of road network and } \\
\text { charging station location, } \mathrm{m}\left(D_{i j}\right)\end{array}$} & \multirow{5}{*}{$D_{i j}<>D_{c}(800 \mathrm{~m})$} & \multicolumn{7}{|c|}{ Decision variable, $\left(Z_{i j}\right)$} \\
\hline \multirow{2}{*}{$\begin{array}{c}\text { Charging } \\
\text { station } \\
\text { location }\end{array}$} & \multicolumn{6}{|c|}{ Covered node } & & Charging & \multicolumn{6}{|c|}{ Covered node } \\
\hline & $\mathrm{A}$ & B & $\mathrm{C}$ & $\cdots$ & $\mathrm{O}^{*}$ & $\mathrm{P}^{*}$ & & $\begin{array}{c}\text { station } \\
\text { location }\end{array}$ & A & B & $\mathrm{C}$ & $\cdots$ & $\mathrm{O}^{*}$ & $\mathrm{P}^{*}$ \\
\hline A & 0 & 1520 & 2510 & $\ldots$ & 11355 & 7230 & & $\mathrm{~A}$ & 1 & 0 & 0 & $\ldots$ & 0 & 0 \\
\hline $\mathrm{B}$ & 2150 & 0 & 990 & $\ldots$ & 11233 & 5710 & & $\mathrm{~B}$ & 0 & 1 & 0 & $\ldots$ & 0 & 0 \\
\hline $\mathrm{C}$ & 4100 & 990 & 0 & $\ldots$ & 10243 & 4720 & & $\mathrm{C}$ & 0 & 0 & 1 & $\ldots$ & 0 & 0 \\
\hline$\ldots$ & $\ldots$ & $\ldots$ & $\ldots$ & $\ldots$ & $\ldots$ & 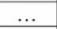 & & $\ldots$ & $\ldots$ & $\ldots$ & $\ldots$ & $\ldots$ & $\ldots$ & $\ldots$ \\
\hline O* & 11355 & 11233 & 10243 & $\ldots$ & 0 & 5735 & & $\mathrm{O}^{*}$ & 0 & 0 & 0 & $\ldots$ & 1 & 0 \\
\hline P* & 7230 & 5710 & 4720 & $\ldots$ & 5735 & 0 & & P* & 0 & 0 & 0 & $\ldots$ & 0 & 1 \\
\hline
\end{tabular}

\begin{tabular}{|c|c|c|c|c|c|c|c|c|c|c|c|c|c|c|c|}
\hline \multicolumn{8}{|c|}{ Total demand, vehicles/hour } & \multirow{5}{*}{$Z_{i j} \times h_{i}$} & \multicolumn{7}{|c|}{ Transport demand, vehicle/hour $\left(h_{i}\right)$} \\
\hline \multirow{2}{*}{$\begin{array}{l}\text { Charging } \\
\text { station } \\
\text { location }\end{array}$} & \multicolumn{6}{|c|}{ Covered node } & \multirow{2}{*}{$\begin{array}{c}\text { Sum } \\
\mathrm{m}\end{array}$} & & Charging & \multicolumn{6}{|c|}{ Covered node } \\
\hline & A & B & $\mathrm{C}$ & $\ldots$ & $\mathrm{O}^{*}$ & P* & & & $\begin{array}{c}\text { station } \\
\text { location }\end{array}$ & A & B & C & $\ldots$ & $\mathrm{O}^{*}$ & $P^{*}$ \\
\hline $\mathrm{A}$ & 609 & 0 & 0 & $\ldots$ & 0 & 0 & 609 & & A & 609 & 1059 & 2604 & \begin{tabular}{|l|}
$\ldots$ \\
\end{tabular} & 3107 & 4617 \\
\hline B & 0 & 1059 & 0 & & 0 & 0 & 1059 & & B & 609 & 1059 & 2604 & $\ldots$ & 3107 & 4617 \\
\hline C & 0 & 0 & 2604 & $\ldots$ & 0 & 0 & 2604 & & C & 609 & 1059 & 2604 & $\ldots$ & 3107 & 4617 \\
\hline 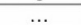 & 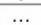 & $\ldots$ & $\ldots$ & $\ldots$ & 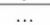 & $\ldots$ & & & 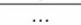 & 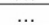 & & & $\ldots$ & & \\
\hline $0^{*}$ & 0 & 0 & 0 & - & 3107 & 0 & 3107 & & O* & 609 & 1059 & 2604 & $\ldots$ & 3107 & 4617 \\
\hline $\mathrm{P} *$ & 0 & 0 & 0 & ... & 0 & 4617 & 9338 & & P* & 609 & 1059 & 2604 & $\ldots$ & 3107 & 4617 \\
\hline
\end{tabular}

Figure 5: Fragment of demand covered model results.

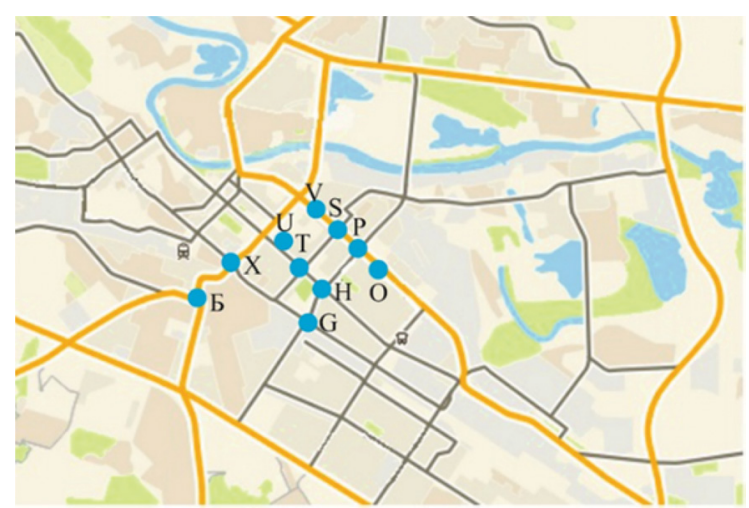

Figure 6: Result of applying the maximum coverage model.

\begin{tabular}{|c|c|c|c|c|c|c|}
\hline \multicolumn{6}{|c|}{$\begin{array}{c}\text { Distance between the node of road network and } \\
\text { charging station location, } \mathrm{m}\end{array}$} \\
\hline $\begin{array}{c}\text { Charging } \\
\text { station } \\
\text { location }\end{array}$ & A & B & C & $\ldots$ & $0^{*}$ & $\mathrm{P}^{*}$ \\
\hline A & 0 & 1520 & 2510 & $\ldots$ & 11355 & 7230 \\
\hline B & 2150 & 0 & 990 & $\ldots$ & 11233 & 5710 \\
\hline C & 4100 & 990 & 0 & $\ldots$ & 10243 & 4720 \\
\hline$\ldots$ & $\ldots$ & $\ldots$ & $\ldots$ & $\ldots$ & $\ldots$ & $\ldots$ \\
\hline $\mathrm{O}^{*}$ & 11355 & 11233 & 10243 & $\ldots$ & 0 & 5735 \\
\hline $\mathrm{P}^{*}$ & 7230 & 5710 & 4720 & $\ldots$ & 5735 & 0 \\
\hline
\end{tabular}
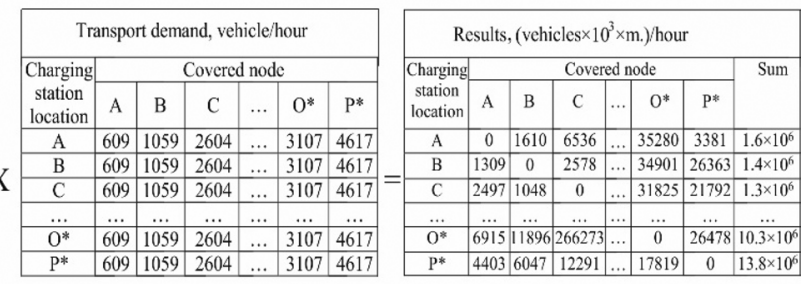

Figure 7: Fragment of p-median model results.

As previously indicated, the presence of points in the road network nodes more distant from the centre contributes to an increase in the value of the covered demand. As a result, the maximum demand coverage model allows only 41,813 vehicles/h to be provided with available charging stations, while the p-median model $-44,538$ vehicles/h. This is the maximum 


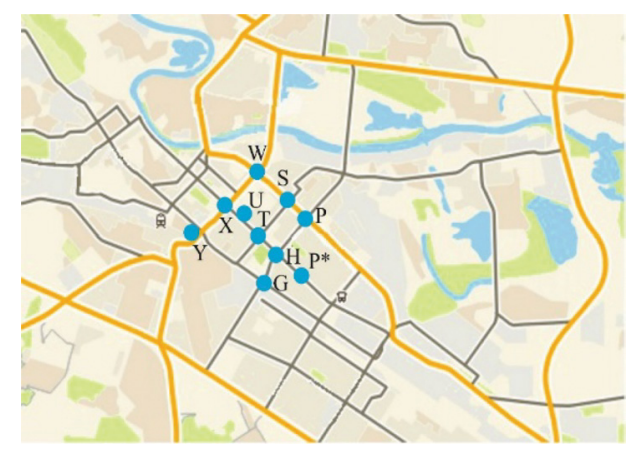

Figure 8: Results of applying the p-median model.

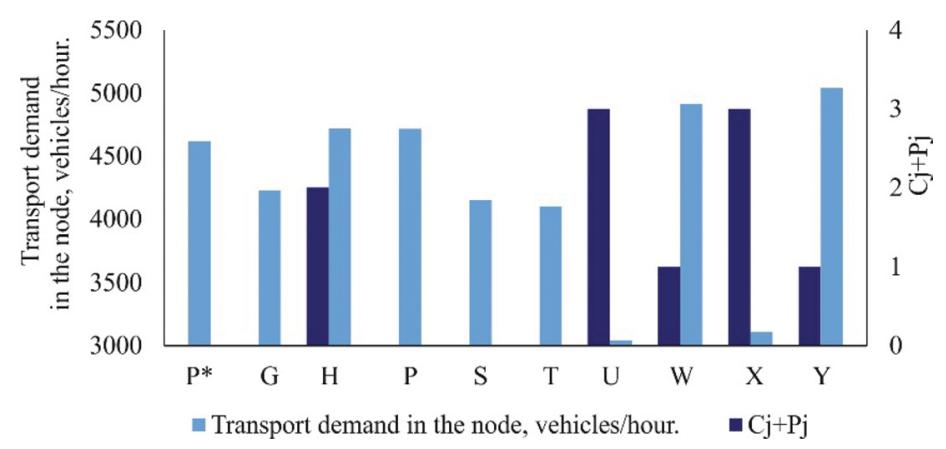

Figure 9: Results of the charging station location.

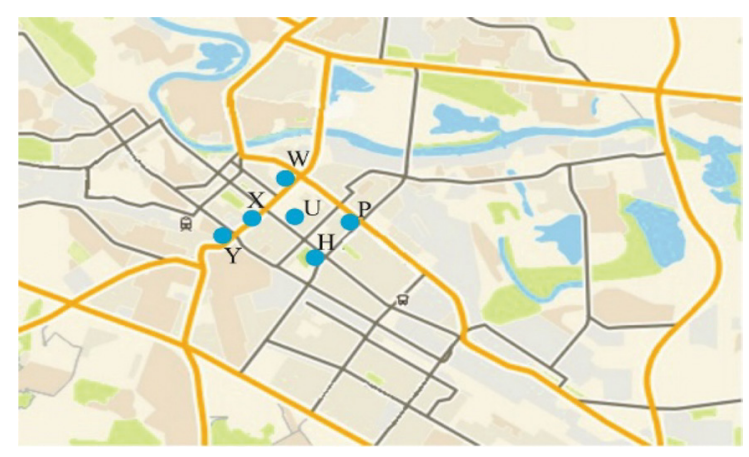

Figure 10: Layout of charging stations in Tyumen.

number of vehicles that cross the network nodes with charging stations. This value influence the probability of electric vehicles staying at the nodes of the road network depends on the traffic flow [11]. A comparative assessment of these values showed that in the future, the p-median model will be applied to develop the model.

According to the diagram for creating a model, at the next stage, the results obtained were evaluated for the availability of complex access roads in accordance with the peculiarities of the traffic organization. The expected charging station locations were also verified against 
decision variables describing the availability of sufficient parking spaces $P_{j}$ and a transformer substation $C_{j}$ (Fig. 9).

In accordance with the objective function describing the second stage of the study, the authors identified only five places in the city to relocate the objects of the charging network that meet all the requirements (Fig. 10). The location for the 6th object was chosen on the basis of the data from the first stage of the study, namely the maximum covered transport demand (Fig. 10). This solution should help maximize the utilization rate of the objects and minimize the idle runs of electric vehicle owners. But it requires the availability of parking space.

\section{DISCUSSION}

Various studies presented the application of an informed approach to the organization of charging infrastructure. In the field of organizing the charging infrastructure for electric public passenger transport, it was proposed to preliminarily analyse the existing infrastructure. Therefore, in this work, as a preliminary stage of the study, as in [10,11], the data on the number of charging sessions performed by the existing charging infrastructure were analysed.

In the course of developing the algorithm for the location of the charging network objects, an integrated approach was elaborated, which until now has not been discovered in the analysis of previous studies. It took into account the data on the centres of attraction of the population and nodes of maximum transport demand, as in [13], and also the peculiarities of the city's power distribution network [19]. It additionally made it possible to assess the likelihood of free parking spaces for charging an electric vehicle and the complexity of the access road, which must be considered as factors that determine the value of the utilization rate of a charging station in cities of the Russian Federation.

An assessment of the centres of attraction of the population and the nodes of maximum demand in the development of the model made it possible to prove the applicability of the p-median model, as in $[15,16]$. During this stage of the study, the possibility of using the maximum coverage model was also assessed, which was considered [16]. However, the greater value of the maximum transport demand and the less crowded arrangement of charging stations when using the p-median model proved its applicability in the cities of the Russian Federation.

The features of the city's power distribution network, which were considered in the work and were aimed at minimizing the total cost of the operation of the charging network, consisted of evaluating the availability of a transformer substation near the expected placement of the charging station, which was also previously presented $[18,19]$. However, the authors proposed a numerical estimate of this parameter, as well as the likelihood of a free parking space. The authors evaluate the complexity of the access road by only taking into account the peculiarities of the traffic organization and the road network layout, which at the next stages of the study will also be proposed to be considered using numerical values.

Thus, analysing previous studies and assessing their advantages and disadvantages allowed developing an integrated approach to the optimal location of charging stations in the city, which considers the likelihood of a free parking space at the expected location of the charging station, and the complexity of the access roads to it as additional parameters, which until now has not been done.

\section{CONCLUSIONS}

This paper is the result of one of the stages of a larger study aimed at developing a methodology for substantiating the parameters of urban charging infrastructure for electric vehicles in the city. It presents the stages of developing an algorithm for optimizing the location of 
the charging network objects and the results of its application in Tyumen. In the course of this study, the authors analysed the previous experience and identified some of the main approaches used in the area under consideration-models of maximum coverage or p-median. As a result, these models were built during the first stage of the study. The highest transport demand at the nodes where the objects of the charging network were located was observed in the p-median model. Therefore, this model was adapted to the additional conditions proposed by the authors to reduce the total costs of the charging network and operating costs for owners of electric vehicles.

The assessment of the existing charging network showed the heterogeneity of the distribution of charging sessions among the objects of the charging network, which was associated with the discrepancy of some values to the variable solutions proposed by the authors. As a result, taking into account the developed algorithm, this network location was optimized. This will help to increase the utilization of charging stations and reduce idle runs for electric vehicle owners.

This algorithm is part of a comprehensive methodology for justifying the parameters of urban charging infrastructure for electric vehicles, which also includes the deployment plan. It will be based on the developed algorithm, taking into account the climatic features of the city location, the parameters of the operated vehicle fleet, as well as approaches to population mobility and demography. The application of the developed algorithm to create the deployment plan of the charging infrastructure will be assessed not only in Tyumen, but also in other cities of the Russian Federation.

\section{ACKNOWLEDGEMENTS}

The work was supported by the Ministry of Science and Higher Education, Contract No. 0825-2020-0014.

\section{REFERENCES}

[1] Calise, F., Cappiello, F., Carteni, A., d'Accadia, M. \& Vicidomini, M., A novel paradigm for a sustainable mobility based on electric vehicle, photovoltaic panels and electric energy storage systems: Case studies for Naples and Salerno (Italy). Renewable and Sustainable Energy Reviews, 11, pp. 97-114, 2019.

[2] Leurent, F. \& Windisch, E., Triggering the development of electric mobility: a review of public policies. Europe Transportation Research Review, 3, pp. 221-235, 2011.

[3] Pieriegud, J., E-mobility on-demand in the central and eastern European countries: current trends, barriers and opportunities. Transportation Economics and Logistics, 81, pp. 26881, 2019, DOI: 10.26881.etil.2019.81.12

[4] Innovation Outlook: Smart charging for electric vehicles, International Renewable Energy Agency. [Online]. Available at https://www.irena.org/publications/2019/May/ Innovation-Outlook-Smart-Charging (accessed 17 July 2020).

[5] Sun, X., Li, Z., Wang, X. \& Li, C., Technology development of electric vehicles: a review. Energy, 13, pp. 90, 2020, DOI: 10.3390/en13010090.

[6] Cansino, J., Sanchez-Braza, A. \& Sanz-Diaz, T., Policy instruments to promote electromobility in the EU28: a comprehensive review. Sustainability, 10, pp. 2507, 2018, DOI: 10.3390/su10072507.

[7] Rietmann, N. \& Lieven, T., How policy measures succeeded to promote electric mobility - Worldwide review and outlook. Journal of Cleaner Production, 206, pp. 66-75, 2019. 
[8] Li, M., Ye, H., Liao, X., Ji, J. \& Ma, X., How Shenzhen, China pioneered the widespread adoption of electric vehicles in a major city: Implications for global implementation. WIREs Energy Environment, 2, pp. e373, 2020, DOI: 10.1002/wene.373

[9] Chen, L \& Wu, Z., Study on the effects of EV charging to global load characteristics via charging aggregators. Energy Procedia, 145, pp. 175-180, 2018.

[10] Gimenez-Gaydou, D.A., Ribeiro, A.N., Gutierrea, J. \& Antunes, A.P., Optimal location of battery electric vehicle charging stations in urban areas: a new approach. International Journal of Sustainable Transportation, 10, pp. 393-405, 2016.

[11] Daskin, M. S., Network and Discrete Location. Models, Algorithms, and Applications, John \& Wiley Sons: New Jersey, pp. 124-362, 2013.

[12] Daskin, M. S., What you should know about location modelling. Naval Research Logistics, 55 (4), pp. 283-294, 2008.

[13] Frade, I., Ribeiro, A., Goncalves, G.A. \& Antunes, A.P., Optimal location of charging stations for electric vehicles in a neighborhood in Lisbon, Portugal. Transportation Research Record Journal of the Transportation Research Board, 2252 (1), pp. 91-98, 2011.

[14] Ghamami, M., Nie, Y. \& Zockaie, A., Planning charging infrastructure for plug-in electric vehicles in city canters. International Journal of Sustainable Transportation, 10, pp. 343-353, 2016.

[15] Ko, J. \& Shim, J. S., Locating battery exchange stations for electric taxis: a case study of Seoul, South Korea. International Journal of Sustainable Transportation, 10, pp. 139-146, 2016.

[16] He, S., Kuo, Y. \& Wu, D., Incorporating institutional and spatial factors in the selection of the optimal locations of public electric vehicle charging facilities: a case study of Beijing, China. Transportation Research Part C, 67, pp. 131-148, 2016.

[17] Sweda, T. \& Klabjan, D., An agent-based decision support system for electric vehicle charging infrastructure deployment. IEEE Vehicle Power and Propulsion Conference, 12339422, 2011, DOI: 10.1109/VPPC.2011.6043201.

[18] Ge, S., Feng, L., Liu, H. \& Wang, L., The planning of electric vehicle charging stations in the urban area. International Conference on Electronic \& Mechanical Engineering and Information Technology, 356, 2012, DOI: 10.2991/emeit.2012.356.

[19] Chen, C. \& Hua, G., A new model for optimal deployment of electric vehicle charging and battery swapping stations. International Journal of Control and Automation, 7, pp. 247-258, 2014.

[20] Wolbertus, R. \& Hoed, R., Electric vehicle fast charging needs in cities and along corridors. World Electric Vehicle Journal, 10, pp. 45-54, 2019.

[21] Wang, Y. \& Lin, C., Locating multiple types of recharging stations for battery-powered electric vehicle transport. Transportation Research Part E, 58, pp. 76-87, 2013.

[22] Cruz-Zambrzno, M., Corchero, C. \& Igualada-Gonzalez, L., Optimal location of fast charging stations in Barcelona: a flow-capturing approach. 10th International Conference on the European Energy Market, 13797585, 2013, DOI: 10.1109/EEM.2013.6607414.

[23] Mak, H., Rong, Y. \& Shen, Z., Infrastructure planning for electric vehicles with battery swapping. Management Science, 59, pp. 1557-1575, 2013.

[24] Lam, A., Leung, Y. \& Chu, X., Electric vehicle charging station placement: formulation, complexity and solutions. IEEE Transactions on Smart Grid, 5, pp. 2846-2856, 2014.

[24] Conti, V., Orchi, S., Valentini, M., Nigro, M. \& Calo, R., Design and evaluation of electric solutions for public transport. Transportation Research Procedia, 27, pp. 117124, 2017. 
[25] Fusco, G., Alessandrini, A., Colombaroni, C. \& Valentini, M., A model for transit design with choice of electric charging system. Procedia-Social and Behavioral Sciences, $\mathbf{8 7}$, pp. 234-249, 2013.

[26] Filippo, G., Marano, V. \& Sioshansi, R., Simulation of an electric transportation system at the Ohio State University. Applied Energy, 11, pp. 1686-1691, 2014.

[27] Gorbunova, A. \& Anisimov, I. Optimizing the location of urban charging stations for electric vehicles: case study of the city of Tyumen, Russian Federation. WIT Transactions on the Built Environment, 200, pp. 15-24, 2020. 